\title{
Aspectos genéticos da obesidade
}

\section{Genetics of obesity}

Iva MARQUES-LOPES 1

Amelia MARTI'

María Jesús MORENO-ALIAGA ${ }^{1}$

Alfredo MARTÍNEZ1

\section{R E S U M O}

A obesidade definida como a acumulação excessiva de gordura corporal deriva de um desequilíbrio crônico entre a energia ingerida e a energia gasta. Neste desequilíbrio podem estar implicados diversos fatores relacionados com o estilo de vida (dieta e exercício físico), alterações neuro-endócrinas, juntamente com um componente hereditário. O componente genético constitui um fator determinante de algumas doenças congênitas e um elemento de risco para diversas doenças crônicas como diabetes, osteoporose, hipertensão, câncer, obesidade, entre outras. O aumento da prevalência da obesidade em quase todos os países durante os últimos anos, parece indicar que existe uma predisposição ou susceptibilidade genética para a obesidade, sobre a qual atuam os fatores ambientais relacionados com os estilos de vida, em que se incluem principalmente os hábitos alimentares e a atividade física. A utilização de modelos animais de obesidade, a transferência génica e os estudos de associação e ligamento, permitiram a identificação de vários genes implicados na obesidade.

Termos de indexação: obesidade, genes, mutação, polimorfismo, estudos de associação e ligamento, modelos genéticos de obesidade.

\section{A B S T R A C T}

Obesity, defined as an excessive body fat accumulation, is caused by a chronic imbalance between energy intake and energy expenditure. Several factors have been associated with this energy imbalance, such as life style (diet and physical activity), neuroendocrine disorders, together with the genetic background. The genetic background is a major determinant factor of some congenital diseases and a risk factor for some chronic disorders, such as diabetes, osteoporosis, hypertension, cancer, obesity, and others. The increased prevalence

\footnotetext{
$\overline{1}$ Departamento de Fisiología y Nutrición, Universidad de Navarra. Edificio de Investigación C/ Irunlarrea, 1, 31008, Pamplona, España. Correspondência para/Correspondence to: A. MARTíNEZ.E-mail: jalfmtz@unav.es
} 
of obesity in most countries during the last years, seems to indicate that there is a genetic predisposition or susceptibility to be obese which is increased by environmental and life style factors, mainly by food habits and physical in activity. The use of obesity animal models, genetic transfer and the association and linkage studies leaded to the identification of many genes associated with obesity.

Index terms: obesity, genes, mutation, polymorphism, obesity genetic models, association and linkage studies.

\section{N T R O D U Ç Ã O}

A acumulação excessiva de tecido adiposo (obesidade) deriva de um aporte calórico excessivo e crônico de substratos combustíveis presentes nos alimentos e bebidas (proteínas, hidratos de carbono, lipídios e álcool) em relação ao gasto energético (metabolismo basal, efeito termogênico e atividade física). Nessa acumulação intervêm, tanto os hábitos alimentares e de estilo de vida, os fatores sociológicos e as alterações metabólicas e neuro-endócrinas, como os componentes hereditários ${ }^{1,2,3}$.

Neste sentido, os genes intervêm na manutenção de peso e gordura corporal estáveis ao longo do tempo', através da sua participação no controle de vias eferentes (leptina, nutrientes, sinais nervosos, entre outros), de mecanismos centrais (neurotransmissores hipotalâmicos) e de vias aferentes (insulina, catecolaminas, sistema nervoso autônomo (SNA). Assim, o balanço energético, do qual participam a energia ingerida e a energia gasta, parece depender cerca de $40 \%$ da herança genética ${ }^{4}$, podendo afetar ambas as partes da equação energética (apetite e gasto).

Os progressos científicos indicam que existe uma base genética transmissível, implicada na manutenção de um peso corporal estável ${ }^{5}$, através dos seguintes mecanismos: 1) no controle de péptidos e monoaminas implicados na regulação do apetite; 2) nas variações do metabolismo basal, no efeito termogênico dos alimentos ou na atividade física espontânea e 3) na regulação da utilização metabólica dos nutrientes energéticos, para suprir as necessidades do organismo.

O aumento mundial da prevalência da obesidade atribui-se principalmente às mudanças nos estilos de vida (aumento do consumo de alimentos ricos em gordura, redução da atividade física, etc.), que incidem sobre uma certa susceptibilidade ou predisposição genética para ser obeso ${ }^{6}$. Neste contexto, também o fenótipo da obesidade, do qual se distinguem quatro tipos em função da distribuição anatômica da gordura corporal (global, andróide, ginóide e visceral), é influenciado pela base genética e por fatores ambientais ${ }^{3,4}$. Além disso, desde o ponto de vista evolutivo, os indivíduos com genes "austeros" ou "poupadores" podem ter sido favorecidos, já que a função reprodutora está dependente das reservas energéticas e as pessoas mais resistentes à desnutrição podem ter sobrevivido em maior proporção, durante as épocas de falta de alimentos.

Por último, a co-existência de obesidade em vários membros da mesma família, confirma a participação da herança genética na incidência da obesidade. A probabilidade de que os filhos sejam obesos quando os pais o são, foi estimada em alguns estudos obtendo-se percentagens entre $50 \%$ e $80 \%^{7}$. Confirmam essa hipótese tanto o fato de existirem indivíduos com uma alteração na termogénese, no metabolismo basal ou na activação simpática, como a constatação de poderem os fatores genéticos modificar os efeitos da atividade física sobre o peso e a composição corporal ${ }^{8}$.

\section{E S T R A TÉ G I A S DE I N V ESTIG A ÇÃ O G E N É T ICA DA OBESIDADE}

A epidemiologia genética da obesidade tem como objetivo a discriminação dos rasgos do fenótipo atribuíveis à base genética em relação 
às influências externas do ambiente ${ }^{9}$. As estratégias de investigação dos determinantes genéticos da obesidade incluem métodos muito diversos (Quadro 1). O processo de interrelacionar um gene com um fenótipo torna-se difícil pela baixa densidade de DNA codificante $(<5 \%)$ e pela magnitude do material genético constituinte do genoma humano, assim como pelas possíveis interações entre genes e fatores ambientais ${ }^{10}$.

Quadro 1. Possibilidades de investigação genética da obesidade.

Estudos de síndromes mendelianas
- Autossômico dominante
- Autossômico recessivo
• Ligado ao cromossoma X
Estudos de sistemas modelos
- Animais obesos
- Animais transgênicos
- Cruzamento (QTL): fenótipo vs. genótipo
- Estudos de associação e ligamento
- Segregação familiar

Os estudos de segregação de núcleos familiares, de adoções, e entre gêmeos, assim como de associação genética, confirmam a tese de que o risco de obesidade é superior nos descendentes de pessoas obesas ${ }^{11}$. As investigações relacionadas com doenças de transmissão mendeliana também indicam que a obesidade pode ser uma característica de doenças autossômicas dominantes, recessivas e ligadas ao cromossoma X. Por outro lado, os estudos experimentais, também permitiram identificar alguns genes relacionados com a obesidade, através do genótipo de animais geneticamente obesos (leptina, receptor da leptina, proteína agouti) ou do cruzamento de animais selecionados pelo fenótipo e mediante animais carentes ou que expressam de forma elevada receptores adrenérgicos $\beta 3$, proteínas desacoplantes (UCP'S), fatores de transcrição e diferenciação (PPAR, C/EBP)...), neuropéptido Y (NPY), etc. ${ }^{6,9,12}$.
Diversos estudos com elevado número de famílias com diferentes graus de consangüinidade permitiram quantificar que a associa indicadores objetivos de obesidade (IMC/\%gordura), com a proximidade do grau de parentes $\mathrm{CO}^{4,7}$, sendo o coeficiente de correlação $\left(r^{2}\right)$ baixo entre esposos $(0,10-0,19)$ e tios-sobrinhos $(0,08-0,14)$, aumentando entre pais e filhos $(0,15-0,23)$ e entre irmãos $(0,24-0,34)$. A correlação do Índice de Massa Corporal (IMC) é ainda mais elevado em gêmeos monozigóticos $(0,15-0,42)$ e dizigóticos $(0,70-0,88)$. Ademais, estudos de intervenção dietética, baseados em balanços energéticos positivos e negativos em gêmeos idênticos, assinalam fidedignamente que as diferenças na susceptibilidade à super alimentação crônica ou a periodos de inanição, parecem ser explicadas principalmente por fatores genéticos ${ }^{13,14}$.

As estratégias de identificação de genes implicados na obesidade podem ser ascendentes ou descendentes ${ }^{10}$. A metodologia ascendente, parte do genótipo e tenta observar uma correlação entre um gene ou grupo de genes com o fenótipo; isto é, trata de estabelecer uma relação ou "ligação" entre uma característica genética dentro de uma família e a transmissão do gene/genes. O método descendente, parte do fenótipo (índice de obesidade) e analiza a distribuição ou presença de um determinado gene entre diversos núcleos e grupos familiares para estabelecer o grau de hereditariedade desse caráter. Algumas limitações deste tipo de estudos devem-se à metodologia de avaliação da obesidade (fenótipo) e à natureza epidemiológica destas investigações baseadas em critérios estatísticos e não individuais ${ }^{7}$.

Os estudos de segregação familiar revelam que a hereditariedade do índice de Quetelet (peso/altura²) está na ordem dos $40 \%$, enquanto que as investigações com gêmeos estimam a contribuição genética em 70-80\% ${ }^{13}$. No entanto, estas informações não são suficientes para explicar inequivocamente a origem genética da obesidade, uma vez que as famílias compartem outros fatores implicados nesta, 
como o estilo de vida, os hábitos dietéticos e o meio-ambiente ${ }^{14}$.

A análise do DNA humano para identificar genes relacionados com a obesidade ou outras doenças condicionadas geneticamente, inclui técnicas de clonação e seqüenciação de genes ou fragmentos de DNA, hibridação de ácidos nucleícos, utilização de enzimas de restrição (endonucleases), fracionamentos por electroforese (Southern), amplificação por reações em cadeia com polimerasas $(\mathrm{PCR})$, ou análise de produtos do gene (proteínas), entre outras ${ }^{15}$. A busca de novas mutações implica metodologias mais complexas e específicas, tais como a utilização de seqüências de DNA, análise inespecífica do genoma (DD), análise conformacional de polimorfismos de uma só linha (SSCP) e a electroforese de gradiente ${ }^{16,17}$.

Os avanços tecnológicos dos últimos anos possibilitaram o desenvolvimento da genômica, transcriptômica e proteinômica, ferramentas moleculares que permitem examinar cada estágio do fluxo de informação biológica, de DNA a RNA e, deste, a proteínas até a função biológica ${ }^{18}$. Com tais instrumentos, pode-se avaliar a expressão de milhares de genes/proteínas numa única hibridação, o que se torna de grande utilidade no estudo dos mecanismos moleculares das diversas doenças ${ }^{19,20}$. Alguns investigadores utilizaram também a tecnologia array (DNA chip) para determinar as alterações na expressão de genes associados com a diabetes em ratos magros, obesos e diabéticos. Suas pesquisas indicaram que a expressão de genes adipogênicos era reduzida nos indivíduos com diabetes ${ }^{21}$.

Os microarrays de oligonucleótidos constituem uma nova tecnologia para o estudo do genoma. Neste sentido, realizou-se uma análise parcial da expressão genômica do tecido adiposo em humanos e detectou-se vários genes que até o momento não fora demonstrado expressarem-se no tecido adiposo; tal resultado sugere novos genes implicados na fisiopatologia da obesidade ${ }^{21}$.
TRANSTOR NOS D E TRANSMIS S A O E N D LIANA

As doenças de origem genética classificam-se em três categorias: 1) Alterações cromossômicas; 2) Doenças monogênicas ou de transmissão mendeliana; e 3) Síndromes multifatoriais ou complexas ${ }^{15}$.

As alterações cromossômicas implicam uma ausência, duplicação ou distribuição anormal de um ou vários cromossomas, que resultam em deficiência ou excesso de determinado material genético. Por exemplo, a síndrome de Down (trissomia 21) assim como a síndrome de Turner (só um cromossoma $X$ ), normalmente vêm acompanhadas de baixa estatura.

As doenças monogênicas ou mendelianas, determinadas pela mutação de um único gene, caracterizam-se por um modelo típico de transmissão genética que pode classificar-se como autossômico dominante, autossômico recessivo ou ligado ao cromossoma X. A busca no banco de dados sobre Herança Mendeliana no ser humano (OMIM) indicou 39 entradas que se referem à manifestação clínica de obesidade com a designação de doenças congênitas autossômicas dominantes; 55 entradas, com a designação de transmissão autossômica recessiva; outras $21 \mathrm{com}$ a designação de doenças ligadas ao cromossoma $X^{22,23}$. A localização cromossômica (locus) no genoma humano de pelo menos 16 das doenças mencionadas anteriormente, aparece na bibliografía sobre o assunto.

A síndrome de Prader-Willi (OMIM 176270; 15q) cursa com obesidade dismórfica prematura (1-3 anos), hiperfagia, hipotonia muscular, hipogonadismo, resistência à lipólise, estatura pequena e atraso mental moderado; é ocasionada a síndrome por alterações no braço q do cromossoma 15 paterno ou por duas cópias maternas do mesmo, doença cuja transmissão é autossômica dominante e cuja incidência é de 1 em 30000. Também são autossômicas dominantes a deficiência em leptina (OMIM 164160; 7q) e a síndrome de Schinzel (OMIM 181450; 12q). 
As síndromes de Ahlstrom (OMIM 203800; 2p), Bordet-Biedl (OMIM 209900; 11q, 209901; 16q, 600151; 3p, 600374, 15q) e Cohen (OMIM $216550 ; 8 q$ ), que costumam serem acompanhadas de um fenótipo de obesidade e de outras manifestações dismórficas como a polidactilia e a sindactilia, são autossômicas recessivas.

As síndromes monogênicas ligadas ao cromossoma $X$ incluem as síndromes de Borjeson (301900; Xq) e de Simpson (312870; Xq), entre outras ${ }^{9}$

As últimas síndromes monogênicas descritas, referem-se às mutações no cromossoma 1 , relacionado com o receptor de leptina (LEPR); no cromossoma 2, que afeta a pró-opiomelanocortina (POMC); no cromossoma 5, que altera o gene implicado numa convertase de precursores de hormônios (PC1); e no cromossoma 18, que codifica os receptores de melanocortina 4 $(\mathrm{MCR} 4)^{9,14}$.

As síndromes multifatoriais normalmente afetam vários genes (poligênicos) e a sua expressão pode depender de fatores ambientais. Algumas doenças crônicas, como é o caso da diabetes, da hipertensão e da gota, podem incluir-se neste grupo; a obesidade, como transtorno de etiologia múltipla, também se pode explicar, em alguns casos, como o resultado de uma doença de origem multifatorial com implicações genéticas ${ }^{15}$.

\section{UTILIZAÇÃ O DE MODELOS ANIMAIS}

As investigações com animais de laboratório destinadas à identificação de genes implicados na obesidade e seus homólogos no ser humano, incluem o estudo de modelos animais de obesidade com mutações monogênicas e poligênicas, a caracterização de loci relacionados com a obesidade através do cruzamento de animais com genótipo conhecido e fenótipo obeso e também a produção de animais transgênicos ou knockout de genes candidatos relacionados com a incidência de obesidade $e^{6,12,24}$.
A descrição de animais fenotipicamente obesos com mutações monogênicas permitiu localizar alguns genes e caracterizar a sua participação na obesidade e as conseqüências da sua ausência ou alteração ${ }^{25}$. Assim, os ratos diabético $(d b / d b)$, obeso (ob/ob), Tubby (tub), amarelo $\left(A^{y}\right)$, gordo (fat) e a rata Zucker (fa/fa), permitiram reconhecer genes homólogos no genoma humano, que se podem expressar de forma dominante $\left(A^{y}\right)$ ou recessiva $(d b, o b$, tub, fat).

O fenótipo de obesidade destes animais é variável no que diz respeito ao seu desenvolvimento como nas manifestações e transtornos metabólicos observados ${ }^{1,26}$. Assim, o rato amarelo (agouti) expressa de forma muito elevada a proteína agouti codificada pelo cromossoma 2 , que compete com o hormônio estimulante de melanócitos (MSH) e com péptidos relacionados com a pró-opiomelanocortina. Neste caso a obesidade se instala de forma tardia acompanhada de hiperfagia.

Os ratos obesos (ob/ob), cuja mutação se localiza no cromossoma 6 murino, desenvolvem-se com uma síndrome acompanhada de hiperfagia, diabetes e obesidade, cuja origem se deve à ausência de leptina (LEP) ou à presença de leptina não funcional. Por outro lado, o modelo de obesidade observado no rato $d b / d b$ e na rata fa/fa (Zucker) deve-se a uma resistência à leptina, como conseqüência de alterações no receptor da leptina, causadas por uma mutação no cromossoma 4 do rato ou no cromossoma 5 da rata. Estes animais, além de obesidade, apresentam hiperinsulinemia, intolerância à glicose e alterações neuro-endócrinas e termogênicas, além de hiperfagia e infertilidade. A rata Zucker apresenta algumas variantes, assim como a rata corpulenta, SHR. A mutação presente no gene tub (rato Tubby), localizada no cromossoma 7, produz obesidade de aparecimento lento, uma ligeira resistência à insulina com hipoglicemia moderada e transtornos sensoriais. A ação da mutação parece estar ligada a uma incapacidade para hidrolizar diversos precursores. O rato gordo 
com a mutação fat/fat no cromossoma 8, constitui um exemplo de obesidade tardia, acompanhada de infertilidade e hiperinsulinemia; nele, foi afetada a enzima carboxipeptidase $\mathrm{E}$, responsável pelo processamento de diferentes precurssores de hormônios como a pró-insulina e o POMC.

Os modelos animais poligênicos de obesidade, normalmente são de mais interesse para avaliar as interações da susceptibilidade genética com outras variáveis dietéticas, ambientais e metabólicas, embora a sua interpretação possa ser complexa em certos casos. Os modelos de obesidade com etiologia poligênica incluem, entre outros, os ratos obesos New Zealand, o rato BSB, a rata Osborne-Mendel e a rata do deserto, assim como algumas raças de primatas que costumam desenvolver sobrepeso e obesidade pela ingestão de diversas dietas ou como conseqüência da idade ${ }^{4}$.

Os modelos animais de obesidade permitiram identificar e caracterizar as regiões homólogas nos seres humanos. Assim, os loci implicados na obesidade presentes nos ratos amarelos $\left(A^{y}\right)$, obeso $(o b)$, diabético $(d b)$, gordo (fat) y Tubby (tub) apresentam homologias nos cromossomas 20 (ASP), 7 (LEP), 1 (LEPR), 4 (CPE) e 11 (TULP1/2) do genoma humano, respectivamente.

Os ratos alterados geneticamente, animais que eliminaram ou incorporaram ao seu genoma fragmentos específicos de DNA, permitiram verificar a função de alguns genes relacionados com a obesidade, através da expressão aumentada, anulação ou regulação de diversos genes ${ }^{6}$. Neste sentido, diversos laboratórios criaram animais transgênicos com um fenótipo de obesidade, induzido por inibição do receptor de glicocorticóides, expressão aumentada de $\mathrm{CRH}$ e de ACTH, expressão aumentada da proteína agouti e do receptor GLUT-4; ou por bloqueio da expressão de UCP e do receptor adrenérgico $\beta 3$, bombesina e serotonina, assim como da metalotioneina. Também se descreveram animais transgênicos em que o fenótipo se caracteriza por uma redução da gordura corporal através da expressão aumentada de LPL, UCP e da enzima PEPCK ou pelo desenvolvimento de animais knockout para GLUT-4, fração Rllb da proteinquinase $A$, hormônio concentrador de melanina (MCH) e do neuropéptido Y (NPY). Existem, ainda, animais transgênicos vinculados aos estudos de controle da termogênese (adrenalina), da tolerância à glicose (TNF- $\alpha$ ) e da diferenciação celular (C/EBP).

É necessário prestar atenção às limitações destes modelos transgênicos para validar a função fisiológica de um determinado gene. O bloqueio ou expressão aumentada de um gene realiza-se em etapas muito precoces do crescimento, afetando todos os tecidos do organismo; além disso, também podem existir mecanismos compensatórios para substituir a função desse gene $^{12}$. Para atenuar estas limitações existem atualmente novas estratégias genéticas que permitem a ativação e/ou desativação do gene ou tecido em questão e que podem conduzir a uma melhor compreensão da função do referido gene $e^{9,27,28}$.

Outro método, desenhado inicialmente para a genética vegetal, conhecido como seleção de locus por caracteres quantitativos, foi convenientemente utilizado para identificar loci com influência sobre o fenótipo da obesidade. Esta estratégia requer o cruzamento de duas raças (de ratos, ratas, etc.) com genomas conhecidos; posteriormente, a análise do fenótipo obtido, através de determinações do peso, gordura corporal, adiposidade, identifica as regiões cromossômicas implicadas na hereditariedade dessa característica e as suas possíveis homologias no genoma humano ${ }^{11}$.

A utilização destes métodos permitiu a identificação de pelo menos 55 loci implicados na transmissão genética da obesidade (e os seus homólogos no homem), alguns deles dependentes da dieta e de outros poligênicos localizados principalmente nos cromossomas humanos 1,3 , $5,7,8,10,11,12,14,17,20$, e $X^{6,9}$. 


\section{TRA N S FER Ê N CIA G Ê N I CA E OBESIDADE}

O fundamento teórico de uma nova estratégia terapêutica, consiste em incorporar um gene ou fragmento de DNA no interior de determinada célula15,16. Esta técnica poderia permitir o tratamento genético da obesidade, nos casos em que a causa seja a ausência ou deficiência de um gene implicado na sua etiologia; isto se faria mediante a substituição ou incorporação de um determinado gene cuja atividade seja deficiente ou inadequada. Um exemplo desta possibilidade consiste em induzir determinadas células (por exemplo, músculo) a produzir grandes quantidades de uma proteína através da incorporação de um determinado gene ou fragmento de DNA no seu núcleo celular. Os métodos de introdução de material genético incluem vetores virais (adenovirus, herpes vírus e outros) e não virais (lipossomas, conjugados DNA-proteínas). A transferência do material pode realizar-se ex vivo a células cultivadas, para posterior transplante ao receptor; ou in vivo, mediante a transferência direta (injeção) do vetor com o gene para as células do receptor. Assim, uma vez que a transferência de DNA para as miofibrilhas pode induzir a expressão de genes exógenos, injeções intra-musculares de plásmidos com cDNA específicos foram utilizadas como método de produção de diferentes proteínas: fatores de coagulação, enzimas, citoquinas, hormônios, etc. Um exemplo da possibilidade desta técnica deu-se na indução da produção de leptina em músculo, depois da incorporação do seu gene nesse tecido ${ }^{29}$.

A leptina, sintetizada e segregada pelo tecido adiposo, funciona como um sinal aferente de saciedade, que atua sobre o hipotálamo, regulando o apetite e o metabolismo e, portanto, controlando a massa gorda corporal ${ }^{30,31}$. Assim, os ratos ob/ob que apresentam uma mutação neste gene, são animais obesos, nos quais a administração repetida de leptina induz uma redução do apetite e do peso corporal. Por outro lado, o tratamento in vivo com leptina aumenta a taxa de lipólise e o consumo de oxigênio nestes animais. Neste sentido, um vetor de expressão plasmídica com cDNA de leptina, administrou-se no músculo tibial da pata traseira dos ratos, em conjunto com o promotor de citomegalovirus e do elemento regulador da cadeia leve da miosina. Os efeitos da injeção do gene da leptina e a sua incorporação ao músculo, revelam uma redução significativa do apetite depois da injeção de DNA, assim como também uma diminuição do peso corporal. Em relação aos animais controle os animais submetidos à terapia gênica com leptina, aumentaram tanto a leptinemia como o consumo de oxigênio in vitro e a lipólise basal ${ }^{29}$.

Estes resultados confirmam que a leptina funcional pode ser produzida pelo músculo e liberada na circulação sangüínea; isto reforça a hipótese de que a leptina contribui aos efeitos de regulação do peso e da gordura corporal, podendo constituir-se numa via de aplicação da terapia gênica no tratamento da obesidade.

\section{ESTUDOS DE ASSOCIAÇÃ O E LI G A M E N T O}

Os métodos de associação e ligamento genético constituem instrumentos valiosos para identificar o componente hereditário da obesidade $^{11,32}$. Os estudos de associação referem-se à busca de relações estatísticas entre um polimorfismo genético e um determinado fenótipo, geralmente entre indivíduos sem parentesco. A estratégia epidemiológica pode considerar: a comparação entre casos e controles, a análise da variação para loci específicos ou a discriminação entre portadores e não portadores em relação a um determinado caráter.

Os estudos de associação aportam informação particularmente importante para a identificação de genes com uma pequena contribuição ao fenótipo de obesidade. No entanto, a sua interpretação deve ser realizada com cautela, uma vez que se exigem valores estatísticamente significativos $(p<0,01)$ para uma associação, esta pode ser devida a uma relação 
causal, em que os loci apareçam associados em conseqüência do azar ou da seleção genética, ou que sejam simples artefatos ${ }^{4}$. Neste sentido, diversos índices do fenótipo da obesidade (pregas cutâneas, peso, IMC, etc.) apresentaram correlações positivas $(p<0,01)$ com alguns genes, como por exemplo, apolipoproteína B (ApoB), apolipoproteína $D(A p o D)$, fator de necrose tumoral $\alpha$ (TNF- $\alpha)$, receptor D2 de dopamina (DRD2), receptor de lipoproteína de baixa densidade (LDLR), receptor de melanocortina 4 (MCR4), receptor de melanocortina 5 (MCR5), leptina e seu receptor (LEPR), receptor de glicocorticóides (GLR), receptor ativado por peroxissomas (PPAR), leptina, receptor adrenérgico $\beta 3$ (ADRB3) e proteína transportadora de ácidos graxos (FABP2).

Por outro lado, os estudos de ligamento genético implicam persistência ou co-segregação de um marcador genético ou locus e de um caráter, durante gerações, dentro da mesma família. Esta estratégia pode utilizar-se com genes candidatos ou com marcadores de polimorfismos e torna-se mais útil quanto mais perto se localiza o marcador em relação ao locus no cromossoma. Este protocolo pode utilizar-se com painéis de famílias nucleares ou através da genealogia, sendo freqüentemente útil no seguimento de fenótipos complexos, caraterizados pela presença de um gene importante ${ }^{11}$. Uma alternativa a este procedimento, consiste no estudo de casais de irmãos em relação a um marcador genético e um fenótipo determinado, já que não requer o conhecimento do modo de transmissão, podendo ser utilizado para diversos loci.

A existência de associação entre o IMC ou outros índices fenotípicos de obesidade (pregas cutâneas, conteúdo em gordura, entre outros) e alguns genes, foi encontrada com uma probabilidade associada inferior a 0,01 para alguns genes como: fosfatase alcalina 1 (ACP1), receptor de glicocorticóides (GR), fator de necrose tumoral a (TNF- $\alpha$ ), leptina, grupo sangüíneo Kell (KEL), receptor 4 e 5 de melanocortina (MC4R e MC5R) e adenosina deaminase (ADA), embora existam algumas discrepâncias, e inclusive resultados controversos em relação a algums deles ${ }^{4}$. Por isso, as expectativas geradas para o gene da leptina e do seu receptor (LEPR) não foram totalmente confirmadas experimentalmente, embora existam evidências de uma implicação em alguns estudos de obesidade extrema em certos grupos étnicos ${ }^{33}$.

Ademais, alguns estudos sugerem que no braço 7q próximo do gene LEP, podem existir marcadores intimamente relacionados com a obesidade. Também a região cromossômica 11q e o cromossoma 20 apresentaram uma possível associação com a obesidade, assim como os cromossomas 2, 5 e 10 com a leptina circulante, onde se encontram os genes da proteína reguladora da glicoquinase (GKRP) e da pró-opiomelanocortina (POMC). A mutação Trp 64 Arg do gene do receptor adrenérgico $\beta 3$ não parece apresentar associação com obesidade em todas as populações estudadas, apesar dos resultados iniciais sobre a sua implicação e a sua associação consistente com uma diminuição do metabolismo basal'11.

Além disso, existem três marcadores adjacentes à proteína desacoplante 2 (UCP2) que apresentaram um certo ligamento com o metabolismo basal dos seus portadores. A proteína desacoplante 3 (UCP3) também está sendo implicada no controle do gasto energético e, indiretamente, na obesidade ${ }^{29}$, assim como o receptor ativado por peroxissomas (PPAR) em estudos de epidemiologia genética ${ }^{34}$.

\section{AP A GENÉTICO DAOBESIDADE}

O mapa genômico descreve a ordem dos genes ou de determinados fragmentos de DNA (marcadores), assim como os espaços não codificantes em cada cromossoma ${ }^{16}$.

O nível mais baixo de resolução corresponde aos mapas de ligamento genético, que só mostram a localização relativa de marcadores de DNA ou genes, enquanto que os 
mapas físicos descrevem a posição exata no cromossoma correspondente, com distâncias que se medem em pares de bases. Os métodos para o traçado genético incluem, entre outros: hibridação in situ, remoção de uma parte ou restrição de regiões cromossômicas e isolamento de cromossomas artificiais em leveduras ${ }^{15}$. O traçado do mapa genético da obesidade supõe identificar os loci onde residem os distintos caracteres envolvidos na etiologia da obesida$\mathrm{de}^{9,35}$. Diversas investigações, utilizando diferentes protocolos e metodologias, identificaram mais de 430 genes e diversos marcadores genéticos implicados na obesidade (Figura 1).

As investigações relacionadas com doenças de transmissão por genética mendeliana acompanhada de manifestação clínica de obesidade, mutações monogênicas em animais geneticamente obesos, análises genéticas inespecíficas, experiências com cruzamento de animais, e os estudos de associação e ligamento com genes candidatos, indicam que todos os cromossomas do genoma humano contêm loci relacionados com a obesidade, exceto o cromossoma $Y^{6,26}$. Assim, alguns cromossomas $1,2,6,8,11,20$ apresentam pelo menos três loci relacionados com a obesidade nos braços $p$ e $q$ cromossômicos; existem outros, em que só um dos braços possue 3 loci ( $3 p, 4 q, 5 q, 7 q, 12 q$, $13 q, 15 q, 22 q$ e $X q)$, enquanto que outros cromossomas não têm loci em nenhuma das suas regiões $p / q(7 q, 21 p$ y $22 p)$.

Por outro lado, a participação dos diversos genes no desenvolvimento da obesidade pode afetar o controle do apetite (NPY, leptina, POMC, CCK, MCH, serotonina, dopanina), o gasto energético e a regulação termogênica (ADR2 e 3, UCP1, UCP3, leptina...), assim como a utilização metabólica de substratos combustíveis e sinalização (PPAR, $A P O B, A P O D$, PKA, etc.).

Note-se que existem genes que inicialmente costumava-se relacionar com a obesidade, embora disso não se tivesse estabelecido uma implicação firme e outros genes, cujos estudos

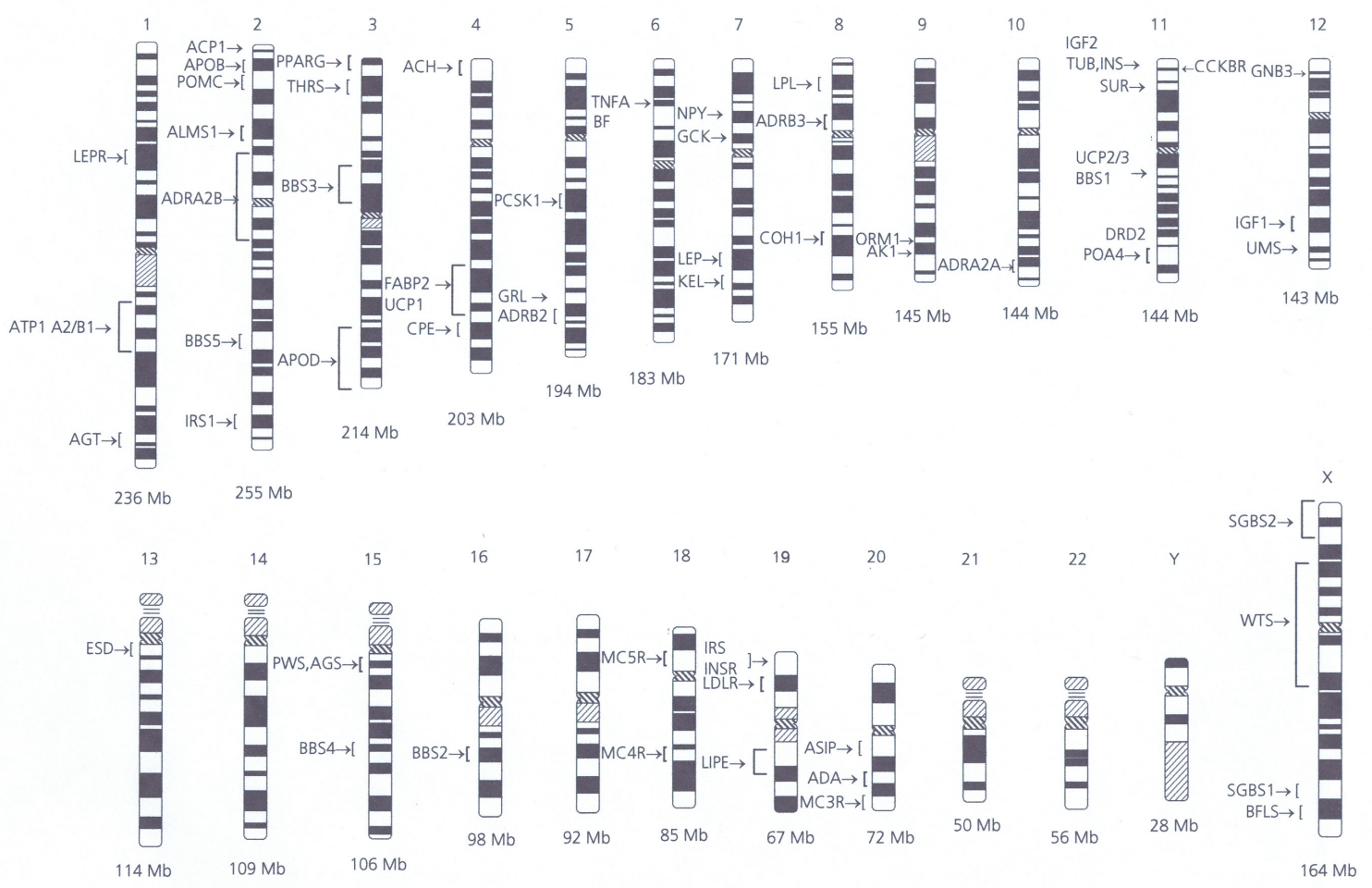

Figura 1. Mapa genético da obesidade. 
apresentaram resultados controversos. Entre eles se incluem os seguintes: genes da proteína desacoplante 1 (UCP1), receptor adrenérgico $\beta 2$ (ADB2), insulina (INS), seu receptor (INSR) ou o sustrato do receptor de insulina (IRS-1), receptor 1 e 5 do neuropéptido Y (NPY1R e NPY5R), ATPase-1 (ATP1), receptor de colecistoquinina A (CCKAR), transportador GLUT-1 (GLUT-1), proteína Tubby (TUB/TULP1/2), inibidor da atividade de plasminogênio -1 (PAI-1), fator semelhante à insulina 2 (IGF-2), proteína agouti e moléculas implicadas na diferenciação de adipócitos (CEBP/PPAR), entre outros ${ }^{11,32,36}$.

\section{O N C L U S Ã O}

Diversos estudos demonstram de forma evidente a participação do componente genético na incidência da obesidade. Estima-se que entre $40 \%$ e $70 \%$ da variação no fenótipo associado à obesidade tem um caráter hereditário. A influência genética como causa de obesidade pode manifestar-se através de alterações no apetite ou no gasto energético. As investigações sobre a implicação genética na prevalência da obesidade utilizaram, ao longo dos últimos anos, diferentes estratégias metodológicas: estudo de modelos animais e extrapolação a regiões homólogas do genoma humano; associação e ligamento de genes candidatos em estudos epidemiológicos; investigações de genes de transmissão mendeliana com manifestações de obesidade, além dos métodos baseados na análise inespecífica de genoma de indivíduos obesos em relação a controles.

A utilização destes protocolos permitiram revelar a existência confirmada de pelo menos 30 genes envolvidos na obesidade e a possibilidade da implicação de mais alguns. Os genes que por seu papel na obesidade atraíram maior atenção nos últimos tempos, foram: o gene da leptina (LEP) e seu receptor (LEPR), as proteínas desacoplantes (UCP2 e 3), moléculas implicadas na diferenciação de adipócitos e transporte de lipídios (PPAR, aP2). Também outros, relacionados com o metabolismo, como é o caso da adenosina desaminase (ADA), da fosfatase ácida (ACP1), do fator de necrose tumoral a (TNF- $\alpha$ ), de determinados neuropéptidos hipotalâmicos e seus receptores (MCR3,4 e 5, POMC, NPY) e dos receptores adrenérgicos (ADRB2 e 3).

A maior sobrevivência dos indivíduos obesos e a influência das reservas de gordura na fertilidade em situações de falta de alimentos, podem ter sido em parte responsáveis por uma seleção natural de pessoas com tendência à obesidade.

\section{REFER Ê N CIAS}

1. Martínez JA, Frühbeck G. Regulation of energy balance and adiposity: a model with new approaches. J Physiol Biochem 1996; 52:255-8.

2. Marques-Lopes I, Ansorena D, Astiasaran I, Forga L, Martínez JA. Postprandial de novo lipogenesis and metabolic changes induced by a high-carbohydrate, low-fat meal in lean and overweight men. Am J Clin Nutr 2001; 73:253-61.

3. Corbalan MS, Marti A, Forga L, Martinez-Gonzalez MA, Martinez JA. Beta(2)-Adrenergic receptor mutation and abdominal obesity risk: effect modification by gender and HDL-cholesterol. Eur J Nutr 2002; 41:114-8.

4. Bouchard C, Pérusse L, Rice T, Rao DC. The genetics of human obesity. In: Bray GA, Bouchard C, James WPT. Handbook of obesity. New York: Marcel Dekker; 1998. p.157-85.

5. Hirsch J, Leibel RL. The genetics of obesity. Hosp Pract 1998; 33(3):55-9.

6. Bray G, Bouchard C. Genetics of human obesity: research directions. FASEB J 1997; 11:937-45.

7. Orera M. Aspectos genéticos de la obesidade. In: Moreno B, Monereo S, Álvarez J. Obesidad: presente y futuro. Madrid: Biblioteca Aula Médica; 1997. p.51-69.

8. Macho-Azcarate T, Marti A, Gonzalez A, Martinez JA, Ibañez J. GIn27Glu polymorphism in the beta2 adrenergic gene and lipid metabolism during 
exercise in obese women. Int J Obes Relat Metab Disord 2002; 26:1434-41.

9. Snyder EE, Walts B. Perusse L, Chagnon YC, Weisnagel SJ, Rankinen T, et al. The human obesity gene map: the 2003 update. Obes Res 2004; 12:369-439.

10. Comuzzie AG, Allison DB. The search for human obesity genes. Science 1998; 280:1374-7.

11. Chagnon Y, Pérusse L, Bouchard C. Familial aggregation of obesity, candidate genes and quantitative trait loci. Curr Opin Lipid 1997; 8:205-11.

12. Inui A. Transgenic approach to the study of body weight regulation. Pharmacol Rev 2000; 52:35-61.

13. Bouchard C, Tremblay A. Genetic influences on the response of body fat distribution to positive and negative energy balances in human identical twins. J Nutr 1997; 127:943S-7S.

14. Jackson AS, Stanforth PR, Gagnon J, Rankinen T, Leon AS, Rao DC, et al. Melanocortin 4 receptor sequence variations are seldom a cause of human obesity: the Swedish Obese Subjects, the HERITAGE Family Study, and a Memphis cohort. J Clin Endocrinol Metab 2002; 87:4442-6.

15. Fauci AS, Braunwald E, Isselbacher KJ, Wilson JD, Martin JB, Kasper DL, et al. Harrison's principles of internal medicine. New York: McGraw Hill; 1998.

16. Romeo CM. Genética humana. Bilbao: Universal Deusto; 1995.

17. Macho-Azcarate T, Marti del Moral A, Martinez Hernandez JA. Genetic studies of obesity in humans. Med Clin (Barc) 2000; 115:103-10.

18. Daniel H. Genomics and proteomics: importance for the future of nutrition research. Br J Nutr 2002; 87(Suppl 2):S305-11.

19. Edvardsson $U$, Alexandersson M, Brockenhuus von Lowenhielm H, Nystrom AC, Ljung B, Nilsson F, et al. A proteome analysis of livers from obese (ob/ob) mice treated with the peroxisome proliferator WY14,643. Electrophoresis 1999; 20(4-5):935-42.
20. Sanchez JC, Chiappe D, Converset V, Hoogland C, Binz PA, Paesano S, et al. The mouse SWISS-2D PAGE database: a tool for proteomics study of diabetes and obesity. Proteomics 2001; 1:36-63.

21. Moreno MJ, Martí A, García-Foncillas J, Martínez JA. DNA hybridization arrays: a powerful technology for nutritional and obesity research. $\mathrm{Br}$ J Nutr 2001; 86:119-22.

22. GDB ${ }^{(\mathrm{TM})}$ Genome Database database [online] 2002 [cited 2003]. Baltimore (Maryland, USA): Johns Hopkins University, 1190. Available from: http:// gdbwww.gdb.org/-2002

23. Online Mendelian Inheritance in Man, $\mathrm{OMIM}^{(\mathrm{TM})}$. Center for Medical Genetics, Johns Hopkins University (Baltimore, MD) and National Center for Biotechnology Information. Bethesda: National Library of Medicine; 2002.

24. Beales PL, Kopelman PG. Obesity genes. Clin Endocrinol 1996; 45:373-8.

25. Leibel RL, Chung WK, Chua SC. The molecular genetics of rodent single gene obesities. J Biol Chem 1997; 272:31937-40.

26. Naggert J, Harris T, North M. The genetics of obesity. Curr Op Gene Dev 1997; 7:398-404.

27. Kulkarmi RN, Bruning JC, Winay JN, PostC C, Magnuson MA, Kahn CR. Tissue-specific knockout of the insulin receptor in pancreatic beta cells creates an insulin secretory defect similar to that in type 2 diabetes. Cell 1999; 96:329-39.

28. Mauvais-Jarvis F, Kulkarni RN, Kahn CR. Knockout models are useful tools to dissect the pathophysiology and genetics of insulin resistance. Clin Endocrinol 2002; 57:1-9.

29. Marti A, Larrarte E, Novo FJ, Garcia M, Martinez JA. UCP2 muscle gene transfer modifies mitochondrial membrane potential. Int J Obes Relat Metab Disord 2001; 25(1):68-74.

30. Lopes IM, Forga L, Martínez JA. Effects of leptin resistance on acute fuel metabolism after a high carbohydrate load in lean and overweight young men. J Am Coll Nutr 2001; 20(6):643-8.

31. Wauters M, Considine RV, Chagnon M, Mertens I, Rankinen T, Bouchard C, et al. Leptin levels, leptin 
receptor gene polymorphism, and energy metabolism in women. Obes Res 2002; 10:394-400.

32. Hasstedt SJ, Hoffman M, Leppert MF, Elbein SC. Recessive inheritance of obesity in familial non-insulin-dependent diabetes mellitus, and lack of linkage to nine candidate genes. Am J Hum Genet 1997; 61:668-77.

33. Farooqi S, Rau H, Whitehead J, O'Rahilly S. ob gene mutations and human obesity. Proc Nutr Soc 1998; 57:471-5.

34. Ristow M, Müller-Wieland M, Pfeiffer A, Krone W, Kahn R. Obesity associated with a mutation in a genetic regulator of adipocyte differentiation. N Engl J Med 1998; 339:953-9.

35. García F, Margareto J, Marti A, Martínez JA, De Miguel $C$. Expresión diferencial de genes en la obesidad inducida por la dieta en ratas. Proc SEB 1998; p.169.

36. Clément $\mathrm{K}$, Dina $\mathrm{CH}$, Basdevant $\mathrm{A}$, Chastang N, Pelloux V, Lahlou N, et al. A Sib-Pair Analysis Study of 15 Candidate Genes in French Families With Morbib Obesity. Diabetes 1999; 48:398-02.

Recebido para publicação em 14 de janeiro e aceito em 31 de outubro de 2003. 